\title{
Looking Back at Quantitative Reasoning
}

William Briggs

University of Colorado at Denver, william.briggs@ucdenver.edu

\section{Recommended Citation}

Briggs, William. "Looking Back at Quantitative Reasoning." Numeracy 14, Iss. 2 (2021): Article 3. DOI: https://doi.org/10.5038/1936-4660.14.2.1392 


\title{
Looking Back at Quantitative Reasoning
}

\begin{abstract}
A teacher looks back on three decades of teaching, pondering, and writing about quantitative reasoning (QR) and shares a few lessons learned. The skills that we teach in QR courses are more important than ever in providing students with a sense of civic virtue: the ability to be engaged and informed citizens in an increasingly complex and quantitative world.
\end{abstract}

\section{Keywords}

quantitative reasoning, quantitative literacy

Creative Commons License

(c) (i) (9)

This work is licensed under a Creative Commons Attribution-Noncommercial 4.0 License

\section{Cover Page Footnote}

William Briggs is a professor emeritus at the University of Colorado at Denver. He is the author of textbooks in quantitative reasoning, statistical reasoning, calculus, problem solving, and computational methods. His work on quantitative reasoning led to a book on the history of the Second Amendment: How America Got Its Guns (University of New Mexico Press). 
It must have been in the late 1980s and early 1990s that my department at the University of Colorado at Denver was tackling an assignment familiar to many mathematics departments at that time: to devise a mathematics course that would satisfy the requirements of a new core curriculum the university had adopted. (The idea of a core curriculum goes back to the University of Chicago in the 1920s. ${ }^{1}$ ) Specifically, it was meant to be a course designed for what today we would call non-STEM students. This exercise had different outcomes on different campuses. Often, the result was just a poorly disguised college algebra course. At other places, it was a chameleon course that varied from one semester to the next depending on the instructor's favorite topics. And on other campuses, it was a collection of topics designed to raise students' appreciation of mathematics. In fact, Math Appreciation and Math for Poets were common and unfortunate names for such courses.

Two reliable features of most non-STEM mathematics courses were that no one was eager to teach them and they were dreaded by students (often taken in the last semester before graduation so students "had to pass" to graduate!). So my colleagues were relieved and thankful when I-still a young faculty member, perhaps looking for approbation from the senior faculty - volunteered to create and teach the course for our department. But I had a few expectations: I wanted the course to be practical, skills-based, and truly beneficial to non-STEM students, rather a 15-week ordeal to be endured just to fulfill a requirement. I believed, maybe naively, that the course could be enjoyable for both the instructor and the students.

I found no guidance in teaching such a course, and a suitable textbook didn't exist. So the obvious first step was to start writing course material for this stillimaginary course. I have a date of June 1992 on a rather hefty set of bound, typeset notes that I wrote to support the course. Several things then happened quite coincidentally. About that time, Jeff Bennett, a new astrophysics Ph.D., was on a curriculum committee at the University of Colorado at Boulder, working on that same assignment, to design a mathematics course for non-STEM students that would satisfy a core curriculum requirement. Jeff had already written course material that attracted the attention of the publisher Addison-Wesley and resulted in a book contract. Then, through a fortuitous connection that neither of us can

1 The University of Chicago's Core Curriculum was adopted in 1931 and is still a hallmark of undergraduate education at that institution. The founding principles of the Core are as relevant as ever today: "The founders of the Core believed that it was the obligation of the modern university to educate flexible minds who would welcome intellectual exploration and see through the temptations of the rigid doctrinal systems that characterized the 1930s. The content of the Core and its sequences is dynamic, and reflects the knowledge and interests of new generations of students and faculty. Yet the founding principle - to teach students how, not what, to think-remains foundational to the College experience and is vital to the intellectual development of University of Chicago students today.” See https://college.uchicago.edu/academics/core-curriculum 
recall, we discovered that we were each working — only a few miles apart—on similar courses supported by piles of potential course material.

I recall meeting with Jeff the first time in a cramped office in the bowels of the $\mathrm{CU}$ football stadium in Boulder. We quickly realized that our ideas for our respective courses were closely aligned and that the course materials we had developed shared much of the same content and spirit. It seemed an obvious match. Our alliance was formed, and I became a coauthor on the book. We began teaching our versions of a new quantitative reasoning course on our respective campuses while writing the first edition of what would become Using and Understanding Mathematics: A Quantitative Reasoning Approach (Bennett and Briggs 2022).

Jeff and I shared many ideas and goals - for our book, for the courses we taught, and about the very meaning of quantitative reasoning (QR). First, the target of these efforts should be non-STEM (or non-calculus-bound) students who will likely never take another mathematics course. We asked, why not give them one final experience that is memorable, positive, and constructive? For that reason, we agreed that the book must emphasize the utility of mathematics above aesthetics. If the beauty of mathematics could be taught along the way, so much the better, but not at the expense of usefulness. By utility we meant that the book must provide skills and knowledge that are relevant to students on three levels: for their upcoming course work, for their future careers, and for their lifetimes; more briefly, for college, careers, and life.

The second guideline we adopted was that the book should be context-driven: rather than building the book around certain areas of mathematics (for example, logic, algebra, discrete mathematics, and statistics), the book should be structured around different areas of interest and application (for example, critical thinking, statistical studies, finances, and risk assessment). Once those topics are chosen, the necessary mathematical tools can be introduced in context. This approach provides motivation for learning certain mathematical skills, as opposed to learning them for their own sake. It also avoids the incessant argument about whether it's important to teach algebra in such a course. The answer is to teach algebra (or remind students of algebra) when it is needed, but not because algebra is an essential life skill.

It's surprising that these two guidelines-teaching the utility of mathematics in realistic contexts - go a long way in designing a course or book. During the 1990s, there seemed to be a growing appreciation of the need for QR courses along the lines we proposed. I recall that the 1995 AMATYC report Crossroads in Mathematics (Cohen 1995), supported our efforts. In the same year, the Mathematical Association of America published its report Quantitative Reasoning for College Graduates (MAA 1995). We were glad to have reinforcement in popular literature from John Paulos's enjoyable book A Mathematician Reads the Newspaper (Paulos 1995). And a few years later, I was encouraged that QR might actually be catching on with reports such as Why Numbers Count: Quantitative 
Literacy for Tomorrow's America (Steen 1997) and Mathematics and Democracy: The Case for Quantitative Literacy (Steen 2001), both edited by Lynn Steen, who along with Bernie Madison have been eloquent voices in the campaign for quantitative reasoning.

I have some recollections about writing Using and Understanding Mathematics that might be informative. The fact that we had enough material to fill several books made writing challenging. As all QR teachers and authors know, it's difficult to decide exactly what topics to include given limited time or space, and we spent a lot of time deliberating these questions. The publisher produced a Preliminary Edition of the book that was class-tested. The results of those trials told us we still had an excess of material, so we continued trimming the content and making hard decisions about which topics to exclude. (It's interesting to note that in the 1990s, textbooks did not have websites and online support, so putting extra material online was not an option.)

Here is some of our thinking that went into organizing the book. In a few words, critical thinking is the set of skills required to gather and analyze facts in an organized, unbiased way in order to make and communicate decisions. The American philosopher John Dewey must have had critical thinking in mind when he said, "to maintain the state of doubt and to carry on systematic and protracted inquiry - these are the essentials of thinking. . . . Reflective thinking, in short, means judgment suspended during further inquiry; and suspense is likely to be somewhat painful (Dewey 1910).

Jeff and I agreed that critical thinking had to be a central theme of the book. Logically, it should appear before the mathematical content of the book, but it should also be a thread running through every chapter. Therefore, Chapter 1 is about critical thinking. Ironically, I can still hear students complaining about the difficulty of this material and asking when the mathematics would begin!

Then, turning up the mathematical demands on students slowly, it made sense to show how much could be done using only (calculator-assisted) arithmetic, number sense, percentages, units, and estimation techniques-all skills that students could be expected to bring to the course or to learn quickly. These chapters served the all-important function of building student confidence.

Focusing on immediate life skills, we then introduced a variety of financial topics, such as investments, loans, and budgets. Not surprisingly, students typically find these topics among the most engaging and relevant in the book. The need for statistical literacy for non-STEM students is vital, not only because many students may not have studied statistics in high school, but also because statistical studies abound in the news, in health data, demographics, and polls. Therefore, two chapters on fairly qualitative statistics form a cornerstone of the book.

We believed it is important for students to have a basic understanding of probability and counting techniques as they arise in expected value calculations, 
risk assessment, decision making, gambling, and lotteries. We then reasoned that with increasing confidence and improved skills, students could tackle exponential and linear modeling, illustrating the pervasive role they play in understanding the world around us. This topic also offers a natural opportunity-perhaps optional in some courses - to introduce functions.

Finally, these core topics do not include a wealth of other applications that might be of interest to non-STEM students. Therefore, we agreed that space should be allotted to the mathematics of music and the visual arts, voting, and apportionment. And with that, we had a book that could support a full-year course and leave instructors plenty of options to design their own courses. (Earlier editions of the book included a chapter on graph theory and network analysis. However, instructor reviews indicated that this chapter saw much less use than the other chapters.)

Using and Understanding Mathematics has been continually updated over the years. A book that relies so heavily on data and contemporary issues requires regular revisions so that its applications are fresh and current. However, the basic framework outlined above has hardly changed. It seems to work for many instructors and the book is now being revised for its eighth edition.

Several years after the publication of Using and Understanding Mathematics, I was approached by the same publisher about writing a calculus text - a project that never appealed to me, given the magnitude of the task and the competitive nature of the market. But eventually, I was persuaded to write a sample chapter, and before I knew it, I was writing a book! I realize now that my experience in cowriting Using and Understanding Mathematics provided guidance in writing the calculus book. While maintaining the required level of rigor for a calculus text, I also realized the importance of making it accessible and filling it with motivating applications from many disciplines — all principles of writing a QR book for nonSTEM students.

That last observation leads to another question: what about QR for STEM students? While teaching calculus and even upper division mathematics courses, I have often thought that some (if not all) of those students could benefit from some lessons in critical thinking and quantitative literacy. It is evident that after several years of algebra and geometry, students can develop strong abstract skills, but still struggle with interpreting and solving problems in a real context. Realizing how impractical it would be to add another course to the requirements of a typical STEM student, the best solution is to emphasize QR skills in all mathematics courses.

All that says a bit about my personal history with quantitative reasoning, but the real lessons about teaching QR come in the classroom, where ideas and plans meet the students head-on. In no particular order, here are a few lessons that I learned over many years of teaching: 
- A course based on the above principles is not remedial! I have had many debates about whether algebra is needed to make a good QR course worthy of college credit, but it's a false choice. Such a course is not a mathematics course in the traditional sense. If anything, it is a course in critical thinking and problem solving, assisted by mathematical tools, so comparisons with traditional mathematics courses are distractions. A good QR course is not remedial.

- Similarly, students in QR courses should not be compared to calculus-bound students. Given the motivation, they are just as competent and capable, but in different ways. It's a challenge and a revelation for an instructor to discover the many different, ingenious ways that non-STEM students think and solve problems.

- Following on the previous point, if students in a QR course are deficient, the problem is one of confidence, not cognition. Over and over, I have watched students' performance improve as confidence in their skills increased.

- Student participation in class is essential. An hour of talking and twenty prepared slides is not a good teaching strategy (probably true in most mathematics courses). My own courses were interspersed with group problem solving, discussions, and confidence-building exercises.

- Often, when students encounter difficulty, the problem is not lack of mathematical skills, but rather conceptual barriers. Here is a favorite example that illustrates the point: I tell the (true) story of a CEO who takes an 85 percent pay cut that reduces his salary to $\$ 500,000$. Then I ask, what was his salary before the pay cut? I discovered that the barrier most students face in answering this question is not solving an equation but in simply visualizing a pay cut. Many students are unable to write the sentence "Original salary minus $85 \%$ of original salary $=\$ 500,000$," which is not a mathematical deficiency. However, once students arrive at this sentence, they typically have no trouble solving for the original salary. I saw this sort of stumble frequently and became convinced there is more to problem solving than mathematical skill.

- Use the news! A good way to start any class is by reading a few headlines from a current newspaper to prompt discussions and raise questions. Whether it's financial news, a journalist's account of a statistical study, or an example of exponential growth, news stories ground the course in reality. Here is one example of a problem that came from reading news in class: a story in the New York Times once reported that the percentage of $12^{\text {th }}$ graders who smoked last year increased 20 percent to 22 percent, Question: what was the percentage of smoking $12^{\text {th }}$ graders last year? If this were a made-up statement, students would be less interested. The fact that it's newsworthy makes a difference, and the question itself leads directly to a discussion of the various uses of percentages. Of course, it's a short step from news to fake news, so topics such as fact-checking and media bias have become essential in QR courses.

- Assessment in a QR course is important, and it requires time and thought. High-pressure, in-class exams will not give a reliable measure of student progress. I always put much more emphasis on weekly problem sets on which students could show their work and be given partial credit. It's the most effective method, but also the most time-consuming. Every course I taught also required a 10-15-page term paper on a quantitative subject of the student's choice, graded in part on the quality of the writing. I quickly learned that many liberal arts undergraduates have difficulties writing and need more practice!

- One of the most enjoyable QR courses I taught was done with a psychology faculty member. He represented the non-STEM students in class better than I did, as shown in the different (and often more successful) ways in which he explained ideas to students. We eventually did a study of student engagement in QR courses that told us a lot about student 
attitudes and fears, changing student behaviors, increasing student motivation, and identifying successful teaching strategies (Handelsman et al. 2005). With heavy teaching loads and understaffing, it's difficult to arrange for team teaching, but it is rewarding.

The hope that many of us had a few decades ago was that one-semester QR courses would eventually evolve into interdisciplinary "QR across the curriculum" programs. The vision was that many courses would have a QR theme and would highlight the quantitative dimensions of various disciplines. We discovered that between faculty time constraints, the enormous job of developing innovative course materials, the hoops erected by curriculum committees, and the competing demands for student credit hours, such a goal was a distant horizon at many schools.

However, I believe the goal of "universal QR" is more important than ever. In an earlier paper, I observed that

strong critical thinking skills and quantitative literacy are needed if we are to avoid drowning in the tidal wave of news and information that emanates from both conventional and social media sources. And certainly, navigating the news, evaluating quantitative information, and making sound decisions are part of what it means to be a responsible and engaged citizen. Combining these observations, we can conclude that effective citizenship relies on quantitative literacy. (Briggs, 2018)

This idea of engaged and informed citizenship is often called civic virtue: a collection of knowledge, attitudes, and skills that enable citizens to contribute to their society. Civic virtue has always included the basic knowledge once learned in civics courses: the branches of government, the ways laws are made and enforced, how the courts work, and so forth. However, today, in a world soaked with quantitative information and conflicting news reports-all delivered through multiple media sources - civic virtue necessarily requires quantitative literacy. Today, our students need this enlarged concept of civic virtue so that they can survive in a complex, rapidly changing world. It falls to the schools, colleges, and universities of this country to embrace this vital educational challenge.

\section{References}

Bennett, Jeffrey, and William Briggs. 2022. Using and Understanding Mathematics: A Quantitative Reasoning Approach, eighth edition Boston: Pearson Education.

Briggs, William. 2018. "Quantitative Literacy and Civic Virtue." Numeracy, 11

(2): Article 7. DOI: https://doi.org/10.5038/1936-4660.11.2.7

Cohen, Don (ed.). 1995. Crossroads in Mathematics: Standards for Introductory College Mathematics before Calculus. American Mathematical Association for Two-Year Colleges (AMATYC).

Dewey, John. 1910. How We Think. Heath, Lexington, MA. https://doi.org/10.1037/10903-000 
Handelsman, Mitch, William Briggs, Nora Sullivan, and Annette Towler. 2005.

"A Measure of College Student Course Engagement." The Journal of Educational Research, 98:3, 184-192.

https://doi.org/10.3200/JOER.98.3.184-192

Mathematical Association of America (MAA). 1995. Quantitative Reasoning for College Graduates: A Complement to the Standards.

Paulos, John Allen. 1995. A Mathematician Reads the Newspaper. New York: Basic Books.

Steen, Lynn (ed.). 1997. Why Numbers Count: Quantitative Literacy for

Tomorrow's America. New York: The College Entrance Examination Board. Steen, Lynn (ed.). 2001. Mathematics and Democracy: The Case for Quantitative Literacy. The National Council on Education and the Disciplines. 